() Open Access Full Text Article

\title{
Improved emotional intelligence in perioperative care through simulation-based medical education during anesthesiology residency training: a call for implementation
}

This article was published in the following Dove Press journal:

Advances in Medical Education and Practice

Juli A Lambert'

Allison A Vanderbilt ${ }^{2}$

Thomas J Papadimos ${ }^{3}$

'College of Medicine and Life Sciences, University of Toledo, Toledo, $\mathrm{OH}, \mathrm{USA} ;{ }^{2}$ Curriculum Evaluation and Innovation, Family Medicine College of Medicine and Life Sciences, University of Toledo, Toledo, $\mathrm{OH}$, USA; ${ }^{3}$ Lloyd Jacobs Simulation Center, Department of Anesthesiology, College of Medicine and the Life Sciences, University of Toledo, Toledo, $\mathrm{OH}$, USA
Correspondence: Juli A Lambert College of Medicine and Life Sciences, University of Toledo, 2062 Robinwood Avenue, Toledo, $\mathrm{OH} 43620$, USA

Tel + I 95I 3783588

Email juli.lambert@rockets.toledo.edu

\begin{abstract}
Emotional intelligence (EI) is the processing of emotional information. It reflects the ability to 1) monitor one's own and others' emotions, 2) discriminate among them, 3) and use this information to guide one's thinking and actions. Higher EI contributes to the doctor-patient relationship, increased empathy, stress management, and leadership. Although EI has been shown to be beneficial in a hospital setting, little work has been done specifically on EI and its efficacy in the perioperative period. There are instances during perioperative care where rise and conflict occur, an environment where EI skills can play an important role. Instituting simulation-based training programs that cover critical skills related to EI early in anesthesiology residency may facilitate constructive interactions with interdisciplinary teams, leading to improved outcomes for patients during perioperative care. These programs in EI would also incorporate elements of the Accreditation Council for Graduate Medical Education (ACGME) core competencies, only adding to the benefit for these residents.
\end{abstract}

Keywords: residency, interdisciplinary, Emotional Intelligence, GME, ACGME, simulation

\section{Introduction}

According to the Institute of Medicine, approximately 98,000 Americans die annually due to health care errors. ${ }^{1}$ One of the most cited factors that lead to medical errors is communication. ${ }^{2}$ Miscommunication in the operating room (OR) may be quite detrimental, with mishaps ranging from operating on the wrong site to retained surgical instruments. Thomas et $\mathrm{al}^{3}$ found that nearly $45 \%$ of all operative adverse events stem from poor communication. Emotional intelligence (EI) plays an important role in communication between anesthesiology and surgical teams. EI is the processing of emotional information. ${ }^{4}$ It reflects the ability to 1) monitor one's own emotions and those of others, 2) to differentiate between such emotions, and 3) to use this information to guide an individual's thinking and actions. ${ }^{5}$ In an effort to improve the elements of physician competency, programs that cover critical skills related to EI could be instituted early in anesthesiology residency programs.

The selection of quality applicants into anesthesiology residency programs is strongly influenced by intellectual ability and medical acumen. ${ }^{6}$ The main non-technical skill categories for physicians include communication, teamwork, 
leadership, and decision-making; ${ }^{6}$ skills that have all been shown to correlate with EI. ${ }^{7-9}$ EI has also been associated with clinical skills and patient satisfaction, ${ }^{9}$ and EI abilities mitigate the stress that leads to subsequent physician burnout. ${ }^{8}$ Improving EI during residency training could facilitate effective interactions between team members during the perioperative period and allow for constructive multidisciplinary efforts. Furthermore, interdisciplinary and/or interprofessional teaching approaches during anesthesiology training regarding EI may lead to a more highly efficient and effective practitioner.

\section{The perioperative environment}

The perioperative period provides multiple opportunities for anesthesiologists, surgeons, and other staff to have a divergence of opinion in regard to the optimal preparation of the patient, as well as the handling of challenging intraoperative and postoperative events. Anesthesiology and surgery are both specialties where the "team concept" is vital for patient care.

Training in EI may contribute to a more effective exchange of information in the perioperative period. ${ }^{10}$ It would do so by providing physicians and other health care providers/colleagues the opportunity to handle challenging situations in a simulated environment. A part of managing relationships is learning how to effectively manage and resolve conflict. ${ }^{7}$ Thus, teaching residents how to manage conflict would aid in the learning process, leading to advanced communicative skills and lower adverse events.

\section{Accreditation Council for Graduate Medical Education (ACGME) milestones - residency training}

The ACGME provides the oversight for all Graduate Medical Education (GME) within the United States and Canada. ${ }^{11}$ The ACGME milestones are the foundation for GME that encompass both residency and fellowship programs. Therefore, it is critical to take into consideration the six core ACGME competencies when addressing GME training programs. The six core ACGME competencies are as follows: patient care, medical knowledge, practice-based learning and improvement, interpersonal and communication skills, professionalism, and systems-based practice. In a systematic review Arora et $\mathrm{al}^{5}$ indicated that a practitioner with effective EI was associated with more compassionate and empathetic care delivery (Patient Care), higher-scoring assessments of knowledge (Medical Knowledge), and effective coping with organizational pressures and leadership (Practice-based Learning and Improvement, and Systems-based Practice). EI also contributed to improved teamwork and doctor-patient communication (Interpersonal and Communication Skills and Professionalism). ${ }^{5}$ With these similarities between ACGME core competencies and EI, it is hopeful that applying EI to medical education could be an effective way to teach and assess these critical skills.

\section{Simulation}

Simulation-based training for health care providers is a wellestablished, viable, and efficacious training tool. ${ }^{12}$ Simulations in EI would serve as a way to develop self-awareness and an understanding of others for residents. ${ }^{8}$ Simulation is particularly effective for training non-technical team-working skills, ${ }^{13}$ such as communication, decision-making, leadership, task management, and monitoring. Skills which are known to be critical to effective teamwork and vital to the prevention of error and adverse events in hospitals. ${ }^{14}$ Leaders in medical education have proposed that simulation-based assessments are essential to solving some of these challenges (previously noted earlier), given that they permit the testing of learners' performance in safe and standardized environments. ${ }^{15}$ Cox et $\mathrm{al}^{16}$ reported on a growing body of evidence that suggested the effectiveness of simulation-based training in achieving educational outcomes of various types. Good educational outcomes, from technical skills to specific learner performance-related behaviors, require a protected and proctored experience within a curriculum with proficiencybased goals. ${ }^{16}$

Glymph et $\mathrm{al}^{17}$ indicated that giving anesthesiology trainees the tools to engage with other health care professionals early on in their clinical education will make them more proficient partners in the delivery of perioperative care. Thereby advancing the educational experiences for the health care professionals in training alongside the anesthesiology residents. Training in EI enhances the conflict resolution, communication, and leadership skills needed to improve team-based communication and function. ${ }^{18}$ Unfortunately, current GME rarely offers formal training in EI, with some of the barriers being limitations of existing evidence, a nonstandard way in assessing EI, and lack of awareness for the importance for educating/training physicians in all aspects of EI. ${ }^{4,5,9}$

Incorporation of EI into an anesthesiology residency curriculum would be most effective with a longitudinal approach. Examples of EI scenarios may include interactions with a 
passive/agreeable colleague, a more moderate colleague with questions, or an aggressive/argumentative colleague. The challenge is using the interactive scenarios to help the learner grow, rather than to make them frustrated in order to minimize poor personal interactions by recognizing and self-correcting non-productive behavior. ${ }^{19}$ These scenarios could be supplemented with a series of lectures on EI. One study supported annual or semiannual workshops, weekly or monthly seminar series, community service experiences or externships, or a combination of these components as an effective way of teaching EI. ${ }^{7}$

The residents can practice their non-technical skills and receive feedback from both an attending physician within anesthesiology and other specialties. The scenarios need to be followed by debriefing to discuss the outcomes of the cases and allow residents to reflect on their interpersonal styles and receive constructive criticism. ${ }^{8}$ Useful information is also gained by analyzing the reactions of others experiencing the same environment, such as nurses or other providers who participate in the scenarios as learners or confederates (players/actors who knowingly aggravate or ameliorate the circumstances of the scenario). ${ }^{19}$

\section{Measurements of EI}

There at least ten ways to measure EI. ${ }^{20}$ Two effective methods are the Emotional Quotient Inventory (EQ-I 2.0) and the EQ-360, which were created to assess the Bar-On model. ${ }^{20}$ The Bar-On model, which describes EI as "an array of interrelated emotional and social competencies, skills and behaviors that impact intelligent behavior", is divided into two parts. ${ }^{21}$ The first part is conceptual, and the second part is psychometric. In other words, the first part is theoretical, and the second part measures EI based on the theory and then assesses the EI. These two parts of the model have also been referred to as "(a) the Bar-On conceptual model of emotional-social intelligence and (b) the Bar-On psychometric model of emotional-social intelligence respectively, while (c) the Bar-On model of emotional-social intelligence refers to both the conceptual and the psychometric components of this model combined together into one inseparable entity". ${ }^{21}$ The EQ-360 assessment provides an analysis that is deeper. Here, those who work with the assessed trainee also provide feedback. When observer ratings are compared with the EQ-I 2.0 self-report, a more detailed portrait of the individual becomes evident. Those evaluating the subjects will need to investigate the measurement method that serves them and their institution the best.

\section{Conclusion}

Emotional awareness and emotional management help mitigate conflicts by maintaining appropriate relationships within a team. ${ }^{8}$ Discord among health care providers can result in potentially avoidable medical errors. Effective EI contributes to the doctor-patient relationship, increased empathy, stress management, and leadership. ${ }^{5}$ Simulation allows for an effective and safe way to teach EI to anesthesiology residents. EI abilities can be taught and sustained over time and serve as a way to measure abilities that affect residency performance. ${ }^{7}$

EI and ACGME competencies complement each other, and incorporating ACGME competencies into EI scenarios through simulation-based medical education will assist in the provision of more effective multidisciplinary cooperation leading to more efficacious patient care and improved outcomes.

\section{Disclosure}

The authors report no conflicts of interest in this work.

\section{References}

1. Scotten M, Manos EL, Malicoat A, Paolo AM. Minding the gap: Interprofessional communication during inpatient and post discharge chasm care. Patient Educ Couns. 2015;98(7):895-900.

2. Vanderbilt AA, Pappada SM, Stein H, Harper D, Papadimos TJ. Increasing patient safety with neonates via handoff communication during delivery: a call for interprofessional health care team training across GME and CME. Adv Med Educ Pract. 2017;8:365-367.

3. Thomas EJ, Studdert DM, Burstin HR, et al. Incidence and types of adverse events and negligent care in Utah and Colorado. Med Care. 2000;38(3):261-271.

4. Qualter P, Gardner KJ, Whiteley HE. Emotional Intelligence: Review of Research and Educational Implications. Pastor Care Educ. 2007;25(1):11-20.

5. Arora S, Ashrafian H, Davis R, Athanasiou T, Darzi A, Sevdalis N. Emotional intelligence in medicine: a systematic review through the context of the ACGME competencies. Med Educ. 2010;44(8):749-764

6. Yule S, Flin R, Paterson-Brown S, Maran N. Non-technical skills for surgeons in the operating room: a review of the literature. Surgery. 2006;139(2):140-149.

7. Taylor C, Farver C, Stoller JK. Perspective: Can emotional intelligence training serve as an alternative approach to teaching professionalism to residents? Acad Med. 2011;86(12):1551-1554.

8. Ishak WW, Lederer S, Mandili C, et al. Burnout during residency training: a literature review. J Grad Med Educ. 2009;1(2):236-242.

9. Talarico JF, Varon AJ, Banks SE, et al. Emotional intelligence and the relationship to resident performance: a multi-institutional study. JClin Anesth. 2013;25(3):181-187.

10. Lingard L, Espin S, Whyte S, et al. Communication failures in the operating room: an observational classification of recurrent types and effects. Qual Saf Health Care. 2004;13(5):330-334.

11. Colt HG, Davoudi M, Murgu S, Zamanian Rohani N. Measuring learning gain during a one-day introductory bronchoscopy course. Surg Endosc. 2011;25(1):207-216.

12. Issenberg SB, McGaghie WC, Petrusa ER, Lee Gordon D, Scalese RJ. Features and uses of high-fidelity medical simulations that lead to effective learning: a BEME systematic review. Med Teach. 2005;27(1):10-28. 
13. Walker ST, Sevdalis N, McKay A, et al. Unannounced in situ simulations: integrating training and clinical practice. BMJ Qual Saf. 2013;22(6):453-458.

14. Reader TW, Flin R, Cuthbertson BH. Communication skills and error in the intensive care unit. Curr Opin Crit Care. 2007;13(6):732-736.

15. Norcini JJ, McKinley DW. Assessment methods in medical education. Teach Teach Educ. 2007;23(3):239-250.

16. Cox T, Seymour N, Stefanidis D. Moving the needle: simulation's impact on patient outcomes. Surg Clin North Am. 2015;95(4):827-838.

17. Glymph DC, Olenick M, Barbera S, Brown EL, Prestianni L, Miller C. Healthcare Utilizing Deliberate Discussion Linking Events (HUDDLE): a systematic review. Aana J. 2015;83(3):183-188.
18. Lee L, Berger DH, Awad SS, Brandt ML, Martinez G, Brunicardi FC. Conflict resolution: practical principles for surgeons. World J Surg. 2008;32(11):2331-2335.

19. Gewertz BL; Pacific Coast Surgical Association. Emotional intelligence: impact on leadership capabilities. Arch Surg. 2006;141(8):812-814.

20. Emmerling, Robert. "Emotional Intelligence Measures." Consortium for Research on Emotional Intelligence in Organizations, 2018, www. eiconsortium.org/measures/measures.html.

21. Bar-On, Reuven. "The Bar-On Concept of EI.” Reuven Bar-On, 2013, www.reuvenbaron.org/wp/the-bar-on-model/the-ei-conceptual-aspect/.

\section{Publish your work in this journal}

Advances in Medical Education and Practice is an international, peerreviewed, open access journal that aims to present and publish research on Medical Education covering medical, dental, nursing and allied health care professional education. The journal covers undergraduate education, postgraduate training and continuing medical education including emerging trends and innovative models linking education, research, and health care services. The manuscript management system is completely online and includes a very quick and fair peer-review system. Visit http://www.dovepress.com/testimonials.php to read rea quotes from published authors.

Submit your manuscript here: http://www.dovepress.com/advances-in-medical-education-and-practice-journal 